\title{
EL TRÁNSITO HACIA (Y LA LUCHA POR) LA DEMOCRACIA MILITANTE EN ESPAÑ ${ }^{1}$
}

\author{
POR \\ MIGUEL REVENGA SÁNCHEZ \\ Catedrático de Derecho Constitucional \\ Universidad Carlos III de Madrid
}

\section{INTRODUCCIÓN}

El de democracia "militante» es uno de esos conceptos cuya imprecisión le hace idóneo para evocar muchas cosas. Es algo que ocurre a menudo con los conceptos de las ciencias sociales y, especialmente, en el ámbito del Derecho Constitucional y demás disciplinas circundantes. Militantes suelen denominarse aquellas democracias que cuentan con medios de defensa para "plantar cara" a quienes aprovechan las posibilidades abiertas por un sistema de libertad para todos, con el fin de intentar destruirlo. En términos de ingenier a constituc,ions señas genéticas están en la Constitución alemana, y son consecuencia directa de las circunstancias históricas que precedieron a su aprobación en 1949.

\footnotetext{
${ }^{1}$ Versiones previas de este trabajo, en lengua inglesa, fueron presentadas a sendas reuniones auspiciadas por el European Consortium for Political Repeledoradas en Edimburgo (Escocia) y Marburgo (Alemania), en abril y septiembre de 2003.
} 
El problema es que actualmente sería difícil encontrar democracias que carecieran de instrumentos de defensa de sus propios valores. Allí donde hay mecanismos de vigilancia y punición - algo apreciable en todas partes sin necesidad de ser entusiasta de Foucault - hay con seguridad formas de poner coto a quienes amenazan la vigencia de tales valores. La calificación de la democracia como militante no se refiere, sin embargo, a esa clase de defensa genérica. Alude más bien a formas específicas de protección, que actúan en la dirección opuesta a la de un sistema de libertades gracias al cual es posible concebir, expresar, y aspirar a ver plasmado cualquier proyecto político. En sus manifestaciones concretas, semejante clase de defensa plantea siempre difíciles cuestiones de validez jurídica; también de legitimidad política y de racionalidad desde el punto de vista de sus resultados prácticos.

En el presente Trabajo comenzamos por discutir los criterios seguidos tradicionalmente para calificar como militante a una democracia. A nuestro juicio, el hecho de que la fórmula siga apareciendo como "la fórmula alemana" para luchar contra la destrucción de la democracia, impide ver hasta qué punto están hoy generalizadas formas muy diversas de democracia militante. La secuencia histórica que va desde la caída de la República de Weimar, hasta las dos célebres sentencias de 1952 y 1956 del Tribunal Constitucional alemán (mediante las que los partidos Nazi y Comunista fueron prohibidos, en aplicación del artículo 21 de la Grundgeset $\$$, tiende a encasillar el concepto de democracia militante en coordenadas bien diferentes de las actuales.

En un segundo Apartado, nos preguntamos si el sistema de defensa de la democracia estatuido en 1978 por la Constitución española cabía ser calificado de militante. Como se deduce del título del Trabajo, intentamos explicar las razones por las cuales dicho sistema no funcionó como tal durante bastantes años. Analizamos luego en qué ha consistido el "tránsito" que da título al trabajo, cuya principal plasmación se encuentra en la nueva Ley de Partidos de 2002. Y finalmente situamos dicha ley en su dinámica de aplicación efectiva durante los últimos meses, caracterizando el nuevo "escenario" abierto por la prohibición de Batasunacomo una lucha por la reafirmación de la democracia militante.

\section{LA GENERALIZACIÓN DE LA DEMOCRACIA MILITANTE}

El concepto de democracia militante procede, como es sabido, del título del trabajo que Karl Loewenstein publicó en 1937 desde su exilio nor- 
teamericano ${ }^{2}$. Es un concepto de combate, concebido para agitar las conciencias frente a la "legalistic self compladedeynas democracias ingenuas, e incapaces de advertir que sus reglas estaban siendo (en las palabras de Loewenstein) el "caballo de Troya a cuyos lomos el enemigo invade la ciudad".

El trabajo no entra en polémica con las ideas que Carl Schmitt venía difundiendo desde algunos años atrás. Loewenstein no quiere hacer teoría; simplemente describe un proceso, advierte sobre lo que él considera como un riesgo inminente, y reclama actuaciones de urgencia para impedirlo. Carl Scmitt, en cambio, hace teoría e identifica (antes de ser coronado como jurista oficial del Reich) lo que él cree que es la fuente del problema. En Legalit $t$ und Legitimptubticado en 1932, vincula las posibilidades de defensa de la democracia a la existencia de un núcleo constitucional inquebrantable y resistente a la reforma. Schmitt denunció la falta de sustancia política de la Constitución de Weimar. Y años más tarde, en contraste con tal indiferentismo, y tras haber pasado por el trauma de los procesos de Nüremberg, creyó ver plenamente confirmada sus tesis en la cláusula de irreformabilidad del artículo 79.3 de la Constitución alemana de la postguerra ${ }^{3}$.

Hoy sabemos que la defensa de la democracia es una cuestión abierta, como pocas, a las falsas "ilusiones del jurista». La experiencia del período de entreguerras acredita que las medidas que entonces se adoptaron, o fueron inútiles, o fueron triviales. Y ello por la simple razón de que su efectividad estuvo condicionada, en proporción inversa, al grado de asentamiento y apoyo de que gozaban los grupos objeto de las medidas ${ }^{4}$.

Pero siendo más amplia nuestra experiencia, y abundando los "estudios de caso", no deja de sorprender que las categorías de fondo continúen tan aferradas a las construcciones doctrinales de los años 30. Nuestro modo de abordar el gran dilema de toda sociedad abierta, el de los límites de su apertura, y el de la protección frente a quienes tienen

2 Karl Loewenstein, "Militant Democracy and Fundamental Rights", The American Political Science RevółwXXXI, no 3, pp. 417 y ss, y vol. XXXI, no 4, pp. 638 y ss., ambos de 1937.

3 Véase la "Introducción», escrita por Carl Schmitt, a una edición del libro publicada en 1968, y a partir de la cual se realizó la versión española; Legalidad y Legitimídad Madrid, Aguilar, 1971, pp. IX-X.

${ }^{4}$ Remito a los diferentes trabajos al respecto de Giovanni Capoccia; entre ellos, "Defending Democracy : Reactions to Political Extremism in Inter.-war Europe», European Journal of Political R,e39e A4t, 2001, pp. 431 y ss. 
como objetivo acabar con ella, se inclina hacia planteamientos en términos de todo o nadarTodo" significa democracia de límites estrictos, sustantiva en fundamentos expresos, y beligerante en extremo a la hora de defenderlos. "Nada" quiere decir democracia de procedimientos, con resonancias kelsenianasy neutral e indiferente hacia los fines.

Tales construcciones dicotómicas llevan a olvidar que entre un extremo y otro hay espacio para categorías intermedias. Y difícilmente encontraremos en la práctica de nuestros días ejemplos que respondan con nitidez a los modelos "ideales" de democracia sustantiva democracia de procedimientosUn trabajo bastante actual, como el de los politólogos norteamericanos Fox y Nolte, sobre "Democracias Intolerantes", es un buen ejemplo de hasta qué punto puede ser deformante seguir aplicando modelos que existen sólo sobre el papel ${ }^{5}$. El trabajo aplica a los mencionados modelos de democracia - sustantivas y de procedimientos - las variables tolerante/militante. Y de ahí resultan democracias de procedimiento (procedural democraci)esolerante(Reino Unido), y militantes (Estados Unidos); e igual para las democracias sustantivas (substantive democracie tolerantes (Francia) y militantes (Alemania). Una dicotomía cuya línea de separación está justamente, como lo estaba en Carl Schmitt, en la posibilidad, o falta de ella, de reformar cualquier precepto de la Constitución.

Haciendo abstracción de lo que hayan podido cambiar las cosas a raíz del 11 de septiembre, uno se pregunta si lo que falla no es el lugar sobre el que tendemos a depositar la mirada. La reforma es un instrumento para la supremacía constitucional. Convierte, como diría Ackerman, a las democracias en democracias dualistałdualist demo cracies)con carriles diferentes para transitar por los momentos de la política "ordinaria", y por los momentos extraordinarios de la política "constitucional" 6 . La reforma introduce estrictas garantías democráticas en el caso de estos últimos, pero es dudoso que de su diseño formal, o de su virtualidad práctica, puedan derivarse argumentos decisivos para cualificar el sentido y las inclinaciones de la vida democrática a cuya defensa sirve. Y ello por no hablar de lo difícil que es hallar ejemplos en los que la reforma haya sido un parapeto eficaz frente a procesos de destrucción de la Constitución.

${ }^{5}$ G. Fox y G. Nolte, "Intolerant Democracies", Harvard International Law Jqurnal vol. 36 (1995), pp. 1 y ss.

${ }^{6}$ Bruce Ackerman, we the People, Transformat,iGanmbridge, Harvard Univesity Press, 1998, Capítulo I (Higher Lawmaking). 
Volviendo a los modelos: ¿no da que pensar que la tolerantfrancia pueda disolver asociaciones políticas mediante simples Decretos del Consejo de Ministros ( $D$ crets mientras que la militantAlemania necesita poner en marcha un complejo procedimiento ante el Tribunal Constitucional? Entre 1936 y 2003, Francia había prohibido no menos de 80 asociaciones políticas. Y Alemania, por su parte, parece haber hecho de los procedimientos de defensa de los artículos 18 (abuso de derecho como causa de la privación individual de determinados derechos) y 21.2 de la Constitución (prohibición de partidos contrarios al orden liberal-democrático) curiosidades históricas u objetos de museo, a los que no ha sentado muy bien el paso del tiempo ${ }^{7}$.

Democracias sustantivas, en el sentido de protegidas frente a la reforma de partes esenciales de la Constitución, son hoy las menos. De los 44 miembros del Consejo de Europa, sólo 14 tienen disposiciones de ese carácter (Armenia, Azerbaiyán, Bosnia-Herzegovina, Chipre, Francia, Alemania, Grecia, Italia, Moldavia, Noruega, Portugal, Rumania, Turquía y Ucrania). En las demás, siguiendo procedimientos más o menos complejos, se puede reformar todo.

Pero ello nada tiene que ver con las formalidades, requisitos y prohibiciones que suelen establecerse con respecto a los partidos políticos. Aquí la regla es la inversa: la gran mayoría de las Constituciones exigen que los partidos sean de una determinada manera, y les prohíben defender ciertas cosas. El repertorio es amplísimo. Va desde la exigencia positiva de respeto a los principios de la soberanía nacional, la integridad territorial, el pluralismo político y el Estado de Derecho, hasta prohibiciones específicas de muy diferente tipo: por ejemplo, "resucitar» ciertos partidos, defender objetivos de carácter exclusivamente regional, poner en peligro el principio de separación de la Iglesia y el Estado, promover la violencia, incitar al odio racial o religioso, etc.

\footnotetext{
${ }^{7}$ El episodio de la (frustrada) prohibición del neonazi Partido Nacional Democrático, NPD, resuelto definitivamente con la Sentencia desestimatoria del Tribunal Constitucional, de 18 de marzo de 2003, así parece atestiguarlo. Los datos de Francia están tomados del Documento parlamentario Rapport fait au nom de la Comisi $n$ d?Enqu te sur les agissements, l?organisation, le fonctionement, les-objetifs du pement de fait dit 'D partement Protection Securit", disponible en http://www.assemblee-nat.fr/dossiers/dps/r1622p03Aakop relación de grupos prohibidos incluida en tal Documento, que está cerrada en mayo de 1999, hay que añadir la decretada en agosto de 2002 contra el movimiento de extrema derecha Unit Radical,ea la que pertenecía el autor del intento de atentado contra Chirac, del 14 de
} 
Recientes Documentos e Informes oficiales del Consejo de Europa permiten ver hasta qué punto es amplio dicho repertorio ${ }^{8}$. También permiten comprobar que el problema de la defensa de la democracia frente a la actividad de los partidos ya ha dejado atrás la secuencia histórica que empezaba en Weimar y terminaba en 1956 con la ilegalización del KPD por el Tribunal Constitucional alemán. Hoy podemos hablar de una generalización de formas de defensa que se concretan, sobre todo, en un sistema de variadas limitaciones al derecho de asociación política. Dichos límites suelen venir expresados en términos negativos y a través de una relación "cerrada" de supuestos. Pero tampoco son infrecuentes las exigencias "positivas" de respeto y lealtad hacia determinados valores.

Todo ello es consecuencia de unas circunstancias políticas bien distintas de aquellas que, en plena Guerra Fría, justificaban la reafirmación democrática contra los totalitarismos de uno u otro signo. La extensión y diversidad de supuestos tienen que ver con las necesidades particulares de cada caso concreto. Pueden responder al deseo de consolidar la transición hacia la democracia después de décadas de gobierno autoritario de un solo partido. También pueden ser instrumentos de salvaguarda frente a tendencias de desintegración territorial; o bien, como ocurre en los Estados de más larga tradición democrática, ser medidas de combate contra quienes cuestionan o atacan aquellos valores que hacen posible la vida en común.

Por suerte para nosotros, ninguna Declaración de derechos se nos muestra hoy sujeta al riesgo de transformarse, como consecuencia de sus supuestos excesos libertar,ier el "pacto suicida", del que hablara el juez norteamericano Robert Jackson en un caso de $1949^{9}$. Los peligros parecen derivar más bien de la inoperancia del legislador, o de su falta de acierto a la hora de configurar el contenido de los derechos. Pero tal riesgo está bastante neutralizado mediante los mecanismos defensa "normalizada» de la

8 Véase European Commission for Democracy through Law (Venice Commission), Guidelines on Prohibition and Dissolution of Political Parties and Analogous Measu adopted at its $41^{\text {st }}$ plenary session (Venice, 10-11 December, 1999), disponible en http://www. venice.coe.int/docs/2000/CDL-INF (2000) 001 -e Nhás?lrecientemente, puede verse también la Resolución 1308 (2002) del Consejo de Europa sobre "Restrictions on Political Parties in the Council of Europe Member States", http://assembly.coe.int/Documents/AdoptedText/TA02/ERES.1308

9 "There is a danger - escribió Jackson en su Opinión discrepante - that, if the Court does not temper his doctrinaire logic withn a little practical wisdom, it will convert the constitutional Bill of Rights into a suicide pact", Terminiello v. City of C,/3377bdoS. 
Constitución. Y además, los controles transnacionales de naturaleza política (Unión Europea y Consejo de Europa) y el sistema de recursos ante el Tribunal Europeo de Derechos Humanos limitan las posibilidades de abuso.

De hecho, hoy puede hablarse de un claro paralelismo entre la opción por un tipo de democracia sustantivamilitanteomo la que aparece en importantes textos internacionales, y la tendencia hacia la generalización de la misma opción en las Constituciones y en la práctica de los países de nuestro entorno ${ }^{10}$.

\section{EL SISTEMA ESPAÑOL DE DEFENSA DE LA CONSTITUCIÓN Y SUS INCOHERENCIAS}

La transición hacia la democracia se hizo en España en un período de tiempo relativamente corto, y con unos resultados que podemos calificar de óptimos. Ello fue posible gracias a una estrategia de reformas paso a paso que llevaron finalmente a la aniquilación del entramado jurídico y político en el que se apoyaba el régimen de Franco. Un ingrediente esencial para el éxito del proceso fue la voluntad generalizada de consenso. Entre quienes lo impulsaban "desde arriba" para ganar credibilidad. $Y$ entre quienes estaban en la oposición, para no comprometer el resultado final que todos deseaban.

El objetivo de cerrar para siempre las divisiones del pasado, mediante el compromiso y el acuerdo, fue aún más intenso durante los meses que transcurrieron desde la celebración de las primeras elecciones democráticas (junio de 1977), hasta la aprobación de la Constitución en el referéndum de diciembre de 1978. Se trataba de ganar para ella la función que raras veces pudo cumplir entre nosotros: la de un símbolo integrador en el que todos se reconocieran ${ }^{11}$.

10 Remito de nuevo al trabajo de Fox y Nolte sobre las Democracias Intolerart bs. autores se les antoja significativo el ejemplo del Pacto Internacional de Derechos Civiles y Políticos, así como el del Convenio Europeo de Derechos Humanos. En ambos, la prohibición de abuso de derecho (artículos 30 del Pacto, y 17 del Convenio), combinado con la sistemática relativa a los límites de los derechos, has dado lugar a elaboraciones jurisprudenciales que cabría calificar de «militantes». Hoy sería ineludible completar la lista con una referencia al artículo 54, el que cierra la Carta de Derechos Fundamentales de la Unión Europea.

11 Una idea que aparece reiteradamente en las contribuciones de los siete autores del Anteproyecto constitucional (Cisneros, Fraga, Herrero de Miñón, Peces-Barba, PérezLlorca, Roca Junyent y Solé), recogidas en el libro 20 a os despu s. La Constituci $n$ cara al siglo, Madrid, Taurus, 1998. 
Pero toda Constitución digna de tal nombre, además de como símbolo de integración, ha de actuar como instrumento normativo. Y la voluntad de incluir, y sumar acuerdos, da a veces como resultado cierta ambigüedad e inconsistencia en lo que se deja escrito.

Me parece que algo así puede decirse del sistema de defensa de la democracia que se aprecia en la Constitución. Su artículo 1 "proclama» valores superiores: libertad, igualdad, justicia y pluralismo político. También habla de la dignidad de la persona, con sus derechos inviolables, como "fundamento del orden político y de la paz social» (art. 10.1) Un lenguaje "fuerte", en el mismo frontispicio del texto constitucional, que no se corresponde con el indiferentismo que denotan sus disposiciones de reforma. Éstas dividen la Constitución en dos: una parte es más fácil de reformar que la otra. Pero esto es sólo a primera vista. Porque en lo que es más difícil de reformar (el Título Preliminar, el núcleo de los derechos fundamentales más importantes, y las disposiciones relativas a la Corona), los requisitos son tan exigentes que, en realidad, parecen concebidos para evitar la reforma. Ello por no hablar de la absurda inclusión de la revisi n totąomo un supuesto "tipificado" de reforma.

Afirmar una cosa y la contraria al mismo tiempo (todo es reformable, pero hay cosas tan difíciles de reformar que mejor no intentarlo) es un síntoma de esquizofrenia política. En el horizonte inmediato, la aplicación del artículo 168 de la Constitución no aparece como plausible. Pero en el terreno de la hermenéutica jurídica, el peso de los argumentos tradicionales otorgó durante muchos años a dicho artículo una importancia decisiva. Decisiva hasta el punto de convertir en meras formalidades "vacías", y de imposible verificación práctica, todo aquello que el artículo 6 de la Constitución exige a los partidos políticos.

Este artículo les pide una estructura interna y un funcionamiento democráticos. Una ley de 1978, aprobada casi al mismo tiempo que la Constitución, también se lo exigía. Y además permitía la disolución judicial de los partidos en dos supuestos: (1) cuando incurrieran en supuestos tipificados como de asociación ilícita en el Código Penal; y (2) cuando su organización o actividades resultaran contrarios a los principios democráticos.

Entre 1978 y 2002 tales disposiciones nunca fueron aplicadas. Pero ahora, tras la aprobación, en junio de 2002, de la nueva Ley de partidos, el Parlamento se apresuró a solicitar ante el Tribunal Supremo la ilegalización del partido Batasuna Se trata de un partido con existencia legal desde 1978, cuya línea política de proximidad a (¿o simbiosis con?) los objetivos y a los medios empleados por el grupo terrorista ETA no ha variado desde entonces. El paso del sistema constitucional español hacia la democracia militante es, sobre todo, una cuestión de cambio profundo en la actitud 
general frente a quienes apoyan o justifican políticamente la violencia terrorista.

Los excesos en las actitudes tolerantes frente a los enemigos de la democracia suelen ser síntoma de escasa tradición democrática. Así lo demuestra, al menos, un trabajo donde se analizan las actitudes frente al radicalismo político de extrema derecha en 12 países europeos ${ }^{12}$. La actitud mantenida frente a Batasunaencaja perfectamente en tal diagnóstico. Durante casi 25 años, se pensó que cuanto más tolerante se fuera, más se iban a debilitar las supuestas razones de justificación del terrorismo. En el régimen jurídico de los partidos, ello se tradujo en la imposibilidad de extraer consecuencia alguna de la falta de lealtad u hostilidad frente a las reglas del juego democrático.

Los argumentos de interpretación constitucional empleados hasta ahora para alcanzar ese resultado distan de ser convincentes. En una Constitución abierta a la reforma de todos sus artículos, han dicho los jueces, no hay fines prohibidos. Y en tales condiciones, la vinculación a la Constitución no puede ser para los partidos más exigente de lo que lo es, con carácter general, para los ciudadanos y para los poderes públicos (artículo 9.1 de la Constitución). Por eso el Tribunal Constitucional quitó cualquier valor sustantivo al requisito de jurar o prometer acatamiento a la Constitución, incluido en las normas parlamentarias, y permitió que los miembros electos de Batasunamanipularan la fórmula a su antojo ${ }^{13}$.

No acatar la Constitución, o hacerlo de mala gana "por imperativo legal», es de por sí un síntoma de deslealtad y "juego sucio" que podría haber sido suficiente para poner en marcha los mecanismos prohibitivos de la ley de partidos. Pero durante muchos años de pasividad tolerante nadie quiso profundizar en lo que la Constitución quiso decir al exigir a los partidos una actuación democrática.

La pasividad política, y no los rasgos "genéticos" del texto constitucional, es la que nos llevó hacia el gran dilema de todos estos años. Tal dilema ha sido: o represión penal por actividades criminales del partido, o falta absoluta de cualquier control, preventivo o ex postrelacionado con las actitudes políticas del mismo. Lo primero está estrechamente relacionado con los principios de responsabilidad individual y aplicación taxativa de la ley penal. Lo segundo se ha considerado incompatible con los impe-

12 Raymond M. Duch and James L. Gibson, «Putting Up With Fascism in Western Europe: A Comparative, Cross-Level Analysis of Political Tolerance», Western Political Quarterl, 445,1992, pp. 237 y ss.

13 Véanse las Sentencias del Tribunal Constitucional 101/1983, y 119/1990. 
rativos de un régimen de libertad en el derecho de asociación, y con las exigencias derivadas de la libertad ideológica y de expresión. Así que el resultado ha sido amparar con todas las garantías constitucionales la conducta de quienes han venido haciendo de la complicidad política con el asesinato, y con los demás delitos de los terroristas de ETA, un ingrediente esencial de su oferta a los electores. $Y$ también ha llevado a financiar generosamente esa conducta con recursos públicos.

El paso hacia la democracia militante representa el intento de acabar con ese sinsentido.

\section{LA NUEVA LEY DE PARTIDOS}

Desde su fundación en 1968, la banda terrorista ETA ha causado en España más de 800 muertos. El asedio del terrorismo fue muy intenso mientras se elaboró la Constitución. Pero la única respuesta que dio la Constitución fue la posibilidad de la suspensión, a título individual, de ciertas garantías. Diversas leyes han desarrollado esa posibilidad, la última de ellas en 1988. Todas fueron cuidadosamente discutidas, y tuvieron que superar un estricto control por parte del Tribunal Constitucional ${ }^{14}$.

La Ley de partidos, aprobada en junio de 2002, es también una norma relacionada con la persistencia del terrorismo en la política española. Pero no se trata de una ley cuya justificación resulte evidente en función de los objetivos que persigue. Esto diferencia a la Ley de partidos de la serie de leyes anti-terroristas aprobadas en desarrollo del artículo 55.2 de la Constitución. En estas últimas, hay una clara razón instrumental: debilitar ciertas garantías para hacer más eficaz la persecución penal de ciertos delitos. En la Ley de partidos, en cambio, la justificación por los fines (contribuir a la lucha contra el terrorismo) no parece tan convincente como la justificación basada en principios.

De hecho, un argumento central en el discurso de quienes se oponen a la ley, es que la prohibición de partidos no es nunca un medio eficaz para aminorar la violencia terrorista o acabar con ella. $Y$ en apoyo de semejante modo de ver las cosas, se aduce a veces, para contraste, el proceso de paz en Irlanda del Norte. En la "vía irlandesa", la capacidad del Sinn Feipara actuar de factœomo portavoz político del IRA, fue esen-

${ }^{14}$ Entre otras, Sentencias del Tribunal Constitucional 25/1981, 199/1987 y 71/1994. 
cial para el éxito de las negociaciones. En el caso del País Vasco, ETA se avino a "decretar" una tregua entre septiembre de 1998 y enero de 2000, pero no renunció durante ella a la "legitimidad de las pistolas", ni demostró pragmatismo ideológico alguno. Batasunano pudo actuar entonces como el Sinn Feiespañol. Pero eso no significa que se debilitara la percepción de una clara simbiosis entre el grupo armado (ETA) y el brazo político (Batasunł. Al contrario: acentuó la sensación de dependencia del segundo con respecto al primero.

Para situarse en el contexto, no hay que olvidar que la totalidad de los miembros de la Mesa Nacionaz algo así como el Comité Ejecutivo de Batasunahabían sido condenados por el Tribunal Supremo, en diciembre de 1997, por el delito de colaboración con banda armada ${ }^{15}$. En 1999, el Tribunal Constitucional anuló la condena, pero no porque considerase como no probado el delito de colaboración, sino porque la pena prevista para el mismo en el Código Penal vulneraba por entonces, a juicio del Tribunal, el principio de proporcionalidad, al no ser susceptible de aplicación gradual en función del tipo de colaboración prestada ${ }^{16}$.

El final de la tregua representó el fracaso de la alianza del nacionalismo no violento, representado por PNV/EA, con el entramado de Batasun姫TA. Y terminó también con la esperanza de que los terroristas se avinieran a dejar las armas. En diciembre de 2000, un Acuerdo "por las libertades y contra el terrorismo", suscrito por el PP y el PSOE, hablaba ya de la posibilidad de impulsar reformas legales contra las «actitudes y comportamientos que constituyeran objetivamente colaboración o incitación al terrorismo». Un primer fruto del Acuerdo fue la reforma del Código Penal para hacer mucho más nítida la definición del delito de exaltación del terrorismo. Con ello se hizo posible la persecución penal de los promotores de homenajes a los terroristas. Una conducta habitual en Batasuną practicada notoriamente el mismo el mismo año 2000 por su portavoz y máximo dirigente, a raíz de la muerte de cuatro miembros de ETA mientras manipulaban una bomba.

Otro de los objetivos de la reforma del Código Penal, a la que acabamos de referirnos, fue proteger a las víctimas de los delitos terroristas,

15 Los hechos que dieron lugar a la condena de los miembros de la Mesa de Batasunaconsistieron en la difusión de un vídeo, durante la campaña electoral de 1996, en el que tres terroristas de ETA, cubiertos con capuchas, explicaban los puntos de vista oficialde la organización respecto a la situación política del País Vasco.

16 Véase la Sentencia136/1999. Los miembros de Batasunahabían sido condenados a 7 años de prisión. 
y a sus familiares, frente a aquellos actos capaces de producir en ellos sentimientos de "descrédito, menosprecio o humillación» ${ }^{17}$. Este punto de vista, que se refiere a la dignidad de determinadas personas, atañe a los requisitos morales mínimos que se piden al orden democrático de una "sociedad civil». Ésta se nos aparece hoy en el espacio europeo como una nueva abstracción, cuyas condiciones básicas de existencia pueden dar razones para prohibir partidos, sobre bases que no son exactamente las de la democracia militante. Así lo analiza con detalle un magnífico trabajo sobre los paradigmas justificativos (anti-extremismo, republicanismo negativQ "sociedad civil») de la prohibición de partidos ${ }^{18}$.

La voluntad de introducir unos estándares mínimos de moralidad política en el régimen jurídico de los partidos, fue uno de los argumentos de más peso a la hora de justificar la nueva ley. Durante los meses que precedieron a su aprobación, los impulsores de ella la presentaron como una exigencia que la democracia española no podía dejar de atender por más tiempo. Además, muchos de quienes pusieron más entusiasmo en la defensa de la ley, dijeron desconocer, o no tener preocupación, por las consecuencias inmediatas que pudiera producir la ilegalización de Batasuna

Estrictamente hablando, la ley decepciona si se contempla como lo que su nombre anuncia. No es una ley que aspire a regular de manera completa el régimen de los partidos. Falta absolutamente cuanto atañe a la financiación de éstos, y no es lo suficientemente detallada a la hora de desarrollar el requisito de la democracia interna. En cambio, es prolija, hasta lo exasperante, en la regulación de las conductas que pueden dar lugar a una declaración de ilegalidad $^{19}$. Lo que se pide a los partidos es que respeten los valores constitucionales, "expresados en los principios democráticos y en los derechos humanos». Y de ahí descienden los supuestos en los que cabe la declaración

17 Artículo 578 del CP: «El enaltecimiento o la justificación por cualquier medio de expresión pública o difusión de los delitos [de terrorismo] o de quienes hayan participado en su ejecución, o la realización de actos que entrañen descrédito, menosprecio o humillación de las víctimas de los delitos terroristas o de sus familiares, se castigará con la pena de prisión de uno a dos años"

18 Peter Niesen "Anti-Extremism, Negative Republicanism, Civic Society: Three Paradigms for Banning Political Parties", German Law Journą Vol. 3, No. 7, disponible en http://www./germanlawjournal. com

19 Remito a los diferentes análisis ya publicados sobre la Ley; entre ellos, el de Luis María Díez Picazo, "Sobre la constitucionalidad de la Ley Orgánica de Partidos políticos» (http://www.aranzadi.es/online/publicaciones/aja/diario/activos/d050203/coment.html), y el de Eduardo Vírgala, "Los Partidos políticos ilícitos tras la LO 6/2002", Teor a y Realidad Constitucipha-11, 2002, pp. 203 y ss. 
de ilegalidad, cuando las actividades de los partidos representen una amenaza para los principios democráticos.

Durante la elaboración de la ley se suprimieron algunas causas de ilegalización que fueron consideradas demasiado ambiguas y/o excesi$\operatorname{vas}^{20}$. Tras la depuración parlamentaria, lo que ha quedado en la ley es la prohibición de conductas que, de forma reiterada y grave, acrediten simpatía con respecto a los actos violentos o de carácter terrorista. Aunque la ley también se refiere a la prohibición de conductas que supongan "exclusión o persecución de personas por razón de su ideología, religión o creencias, nacionalidad, raza, sexo u orientación sexual", son las conductas relacionadas con el terrorismo las únicas que se contemplan de manera exhaustiva. Así, a título de ejemplo, cuando se habla de "promover, justificar o exculpar los atentados contra la vida o la integridad de las personas", "fomentar, propiciar o legitimar la violencia como método para la consecución de objetivos políticos", "apoyar políticamente la acción de organizaciones terroristas" "colaborar habitualmente con entidades o grupos que actúan de forma sistemática de acuerdo con una organización terrorista", "utilizar (...) símbolos o mensajes o elementos que representen o se identifiquen con el terrorismo", "dar apoyo político expreso o tácito al terrorismo", o «incluir regularmente en sus órganos directivos o en sus listas electorales personas condenadas por delitos de terrorismo».

Como puede comprobarse, la lista de conductas es amplia, repetitiva y manifiestamente mejorable desde el punto de vista de la certeza jurídica. Pero el objetivo de la ley es bien concreto y determinado. Podría resumirse en la idea de que la nueva ley exige a los partidos políticos un precompromiso democr ticexpresado en un claro distanciamiento con respecto al terrorismo. Y para ello, les prohíbe hacer determinadas cosas, y también les obliga a hacer otras. Por ejemplo, adoptar medidas disciplinarias contra cualquiera de sus afiliados con doble militancia en organizaciones vinculadas a un grupo terrorista o violento.

En agosto de 2002, un nuevo atentado mortal de ETA, acompañado de la habitual reacción frente a él por parte de Batasuną dio ocasión para que el Congreso de los Diputados ejercitara la acción de ilegalización prevista en la Ley de partidos ante el Tribunal Supremo. Y, simultáneamente, determinadas actuaciones penales seguidas desde hace tiempo en la Audiencia Nacional contra miembros de Batasunapor el delito de colabo-

20 Concretamente, las que se referían a "fomentar un clima social degradado de enfrentamiento y exclusión», así como a "apoyar a agrupaciones alternativas a las instituciones constitucional y legalmente establecidas». 
ración con banda armada, llevaron a la suspensión cautelar de dicho partido y al cierre de sus sedes.

En la demanda de ilegalización, se describe la larga historia de connivencia política de Batasunacon ETA desde que el partido, con ése u otros nombres, comenzó a actuar públicamente en $1978^{21}$. También se aporta abundante material probatorio. Por su parte, los abogados de Batasuna basaron su defensa en la inexistencia de vinculación orgánica entre dicho partido y ETA; aduciendo también que la Ley de partidos es una ley "de caso único", dirigida ex profesoontra ellos, y que va contra sus derechos fundamentales y contra determinadas garantías constitucionales básicas.

El Estado democrático de derecho tiene unos componentes y unas exigencias vinculantes para todos. A los jueces les impone razonar sus decisiones con base en una técnica jurídica cuidadosa y meditada. Su aplicación del Derecho es siempre susceptible de control, y en este caso no sólo de un control Itimce internpor parte de la justicia constitucional, sino también de carácter transnacional. Pero, por muy sofisticada que haya llegado a ser la técnica jurídica de la libertad en el Estado democrático, nunca podrá ser ciega ante lo que es evidente para cualquiera con someros conocimientos de la vida política española. Y aquí tan evidente es para todos que la Ley de partidos se hizo con el fin de ilegalizar Batasuną como notorio que Batasunay la organización terrorista ETA han mantenido conexiones organizativas y estratégicas que van mucho más allá de la mera coincidencia ideológica.

\section{DESDE EL «TRÁNSITO» HACIA LA «LUCHA» POR LA DEMOCRACIA MILITANTE}

Para entender la complejidad del escenario político y jurídico abierto por la iniciativa de ilegalizar Batasuną es preciso tener en cuenta varios factores. En el plano jurídico, la cuestión sigue abierta. Y ello no sólo porque el asunto ha emprendido ya, por iniciativa del Gobierno vasco, el camino hacia el Tribunal Europeo de Derechos Humanos, sino porque el propio Tribunal Constitucional español tendrá que volver a pronunciarse en los próximos meses sobre el fondo del problema. La razón de ello es que el sistema español hace compatible, como de sobra es sabido, un control abstracto sobre la constitucionalidad de la ley, con una defensa concreta de

21 Está disponible en http://www.basque-red.net/cas/bat/doc/di_ldonde en cambio falta la Contestación presentada por la representación de Batasuna. 
los posibles derechos fundamentales vulnerados en el momento en el que la ley se aplica. Algo que en el caso presente puede dar lugar a Decisiones de fondo reiterativas, sobre todo si tenemos en cuenta que, en el período comprendido entre marzo y mayo de 2003, hemos tenido cuatro importantes Decisiones judiciales sobre la prohibición de Batasunay sus consecuencias prácticas: la del Tribunal Constitucional en el Recurso interpuesto contra la ley por el Gobierno vasco, la del Tribunal Supremo resolviendo la demanda de ilegalización, y de nuevo las del Tribunal Supremo y el Tribunal Constitucional en el conflicto planteado por la impugnación en el País Vasco de determinadas listas electorales, en las elecciones locales de mayo de $2003^{22}$.

En el terreno político, las elecciones locales de mayo de 2003 permitieron no sólo descartar aquellos vaticinios que pronosticaron, tras la prohibición, la imposibilidad de celebrar los comicios en condiciones normales, sino comprobar cuáles ha sido el impacto de la prohibición sobre el clima político y el comportamiento electoral en el País Vasco.

Un argumento jurídico que aparece reiteradamente en la primera de las Decisiones del Tribunal Constitucional, así como en la del Tribunal Supremo, es que la Ley en absoluto supone un paso hacia la democracia militante. Con ello se paga tributo a la concepción más tradicional de tal idea, y se pretende demostrar que, puesto que en la Constitución todo es reformable, todo puede defenderse, siempre que los medios para hacerlo sean legales. Consecuentemente, se insiste mucho en que lo que la ley penaliza es la colaboración material con el terrorismo, demostrada no a través de actos singulares, sino mediante una clara actividad persistente en el tiempo. Y ambas - especialmente la del Tribunal Supremo - hacen un considerable esfuerzo probatorio para demostrar que Batasunahabía incurrido en tal tipo de conducta, incluso tomando sólo como referencia temporal el período que se inició tras la aprobación de la ley en junio de 2002.

El punto débil de una línea argumental sólidamente trabada, radica en la insistencia en resaltar que la ley no persigue ideas. Porque ¿qué pasa si un partido considera legítima la violencia terrorista, frente a otro tipo de violencia, institucional, de clase o de cualquier otro tipo? ¿Resulta apropiado seguir diciendo que la Constitución sería neutral, incluso en tal caso? ¿O es que cabría una reforma constitucional que hiciera de la violencia un instrumento legítimo? Uno de los puntos más discutidos de la ley es el consi-

22 Sentencias del Tribunal Constitucional, de 12 de marzo de 2003 y de 8 de mayo de 2003, y Sentencias del Tribunal Supremo, de 27 de marzo de 2003 y de 3 de mayo de 2003. 
derar el rechazo a condenar atentados como una muestra de apoyo tácito al terrorismo (artículo 9.3 a de la Ley). Si tal cosa sucede sin que se demuestre, al mismo tiempo, una colaboración más fuerte, es difícil mantener que la ley no está penalizando un tipo de expresión, odiosa si se quiere, pero perfectamente legítima desde los condicionantes de un sistema de libertad de expresión.

En realidad el paso que la ley refleja es la justificada respuesta a una situación insostenible. Sus concretas cláusulas prohibitivas del artículo 9 parecen hechas a la medida para expulsar de la escena política a un partido asociado mediante vínculos personales, ideológicos y organizativos, a un grupo terrorista. Y vista así, bien pudiera ocurrirle que acabara haciendo de todo cuanto atañe al grueso de su contenido, una ley de caso único. Frente a los reproches jurídicos basados en ello, el Tribunal Constitucional recurre a la diferencia entre la occasiole la ley, esto es las razones políticas que llevaron a su aprobación, y la ratide la misma, esto es, el contenido objetivo de una ley que desarrolla en términos generales lo que el artículo 6 de la Constitución exige a los partidos políticos.

Pero el paso hacia la militancia contra la complicidad con el terrorismo no se completa mediante una simple ley y su aplicación ad casum. Luego hay que ejecutar las decisiones judiciales, y extraer las consecuencias que se derivan de la prohibición de un partido que venía gozando de considerable apoyo electoral en las circunscripciones del País Vasco ${ }^{23}$.

La respuesta de Batasunffrente a la prohibición fue instaurar una llamada "Plataforma por la Autodeterminación», y promover, de cara a las elecciones, candidaturas independienteon la mayoría de las circunscripciones del País Vasco. La ley electoral así lo autoriza, pero la nueva Ley de partidos políticos también había previsto tal contingencia, añadiendo a la ley electoral un párrafo prohibiendo la presentación de candidaturas a "agrupaciones de electores que, de hecho, vengan a continuar o suceder la actividad de un partido declarado judicialmente ilegal» (artículo 44.4 de la ley electoral, conforme a la redacción dada al mismo por la Disposición Adicional $2^{\mathrm{a}}$ de la ley de partidos). Ello dio lugar a una nueva batalla judicial, que tuvo que ser resuelta con la rapidez propia de la justicia electoral, y que dio lugar a dos nuevas Decisiones del Tribunal Supremo y el Tribunal Constitucional, anulando la mayoría de las listas, con el argumento de que las mismas incluían un buen número de candidatos que habían sido can-

23 Tomando como base las anteriores elecciones locales de 1999, el porcentaje de voto a Batasunafue del 27'49 por ciento en Guipúzcoa, el 16'24 por ciento en Vizcaya, y el $13^{\prime} 91$ por ciento en Álava. 
didatos de Batasuna en anteriores elecciones. Esto ocurría, según el Tribunal Supremo en 241 de las 249 listas «independientes» recurridas por el Fiscal, pero el Tribunal Constitucional rebajó el cómputo hasta 225 listas, por entender que un solo candidato en el total de la lista, o una vinculación con Batasunamuy alejada en el tiempo no era razón suficiente para anular la entera candidatura.

La consiguiente campaña de Batasunaen favor del uso de papeletas nulas, permite especular acerca del apoyo que el partido declarado ilegal aún conserva en el País Vasco. En las elecciones locales de 1999, Batasuna obtuvo un total cercano a los 272.000 votos, incluyendo los resultados obtenidos en el País Vasco y en Navarra. Y en las de 2003, sumando el voto nulo de ambas regiones, la cifra se redujo a 145.850 , de los que 127.335 corresponden al País Vasco. Esas son cifras globales que se prestan a poca discusión. Otra cosa es el cálculo de quién fue el principal beneficiario de la prohibición, pues lo cierto es que en las elecciones de mayo de 2003, todos los partidos que concurrieron a las elecciones en el País Vasco - y de modo especialmente acusado los nacionalistas "legales" - experimentaron un incremento en su porcentaje de voto y en el número de representantes en los Ayuntamientos ${ }^{24}$.

Para no llevar esta contribución más allá de unos límites razonables, no entraremos en tal debate. Simplemente añadiremos que la prohibición de Batasunano parece haber reforzado significativamente la posición de supremacía que ya ostentaba la coalición PNV-EA. Dicha coalición nacionalista viene gobernando en el País Vasco, sola o junto con otros partidos, desde la celebración de las primeras elecciones autonómicas en 1980. Su ambigüedad con respecto al fenómeno terrorista forma parte de una estrategia de confrontación con los partidos "españolistas», que ha encontrado en la prohibición una nueva y fructífera causa. Su falta de colaboración institucional para lograr una completa ejecución de la Sentencia está en la base del el enfrentamiento abierto entre el Tribunal Supremo y el Parlamento vasco (donde Batasunacuenta con 7 escaños), motivado por la negativa de éste a disolver el Grupo parlamentario formado por los representantes de Batasuna.Las argucias legales utilizadas para ello (básicamente la defensa de la autonomía parlamentaria y la falta de una previsión

${ }^{24}$ Ciñéndonos al País Vasco, la coalición nacionalista PNV-EA, incrementó su porcentaje sobre el total de voto válido, desde el 34.16 en 1999 hasta el 43.83 en 2003, y de 1.135 concejales a 1.601; el Partido Socialista, PSE-PSOE, de 18.88 a 22.08, y de 243 a 296; el Partido Popular, de 17.49 a 18.71, y de 223 a 232; e Izquierda Unida, de 4.38 a 7.90 , y de 26 a 79. 
expresa en el Reglamento de la Cámara) importan menos que la deslealtad política manifestada por una posición a la que los propios miembros de Batasunapudieron contribuir mediante sus votos.

La cuasi-ruptura institucional capitaneada por el nacionalismo vasco ha culminado en un plan de reforma del Estatuto de Autonomía (en realidad de reforma de la Constitución por falsa vía), en el que se da un "salto en el vacío", para convertir la posición del País Vasco en un "Estado libre asociado" a España ${ }^{25}$. Durante la campaña electoral, los terroristas de ETA rechazaron el (Ilamado) plan Ibarretxe, y pidieron el voto para las candidaturas "independientes" anuladas por los jueces. El rechazo del plan se basa sobre todo en que éste se refiere sólo a las tres provincias del País Vasco, mientras que ETA mantiene su aspiración a reunificar todos los territorios vascos dispersos en el Estado español (las tres provincias vascas más Navarra), y en el Estado francés (territorios de Behenafarroa, Lapurdi y Zuberoa), para convertirlos en un Estado plenamente independiente. Además, desmintieron que hubieran acordado una tregua encubierta, aunque su comunicado deja entrever sus dificultades para reubicarse en el nuevo escenario producido por la prohibición de Batasunąalgo que puede resumirse en la pragmática idea de que el balance entre lo que ETA aporta a Batasunay su entorno, y lo que ésta tiene que pagar por su relación con ETA, ha comenzado a ser negativo.

\section{CONCLUSIÓN}

Las demandas que Batasuna tiene pendientes ante el Tribunal Constitucional no es previsible que obtengan resultados distintos a los que ya conocemos. El acceso del caso al Tribunal Europeo de Derechos Humanos tampoco parece que pueda alterar la decisión de prohibir, ratificada por los jueces españoles. Especialmente si tenemos en cuenta que los tribunales españoles - Supremo y Constitucional - se apoyaron extensamente en la jurisprudencia de Estrasburgo. Con ocasión de un buen número de prohibiciones de partidos políticos llevadas a cabo por Turquía, el TEDH ha tenido, en efecto, ocasión en los últimos años de ocuparse detenidamente de cuándo la prohibición de un partido resulta legítima desde el punto de vista de los estándares de protección asegurados por el

25 Sobre las implicaciones jurídicas y políticas del Plan, véanse las contribuciones incluidas en el libro Estudios sobre la Propuesta pol tica para la convivencia del 
Convenio. Este mismo año 2003, la importante Decisión de la Gran Sala, en el caso del Partido de la Prosperidad contra Turquía, confirma las tesis que el Tribunal ha venido manteniendo ${ }^{26}$.

El clima post 11 de septiembre favorece sin duda un entendimiento del sistema de libertades donde no cabe connivencia alguna con el fenómeno terrorista. El Gobierno de Aznar (apoyado en esto por la oposición) fue especialmente beligerante en difundir la idea de que Batasunay ETA son la misma cosa. Y fruto de ello, consiguió que tanto el Departamento de Estado norteamericano como la Unión Europea incluyesen a Batasuna en sus respectivas "listas negras" de organizaciones terroristas. Paralelamente a tales esfuerzos diplomáticos, que incluyeron rápidas respuestas a editoriales de prestigiosos periódicos sobre el "problema vasco" ${ }^{27}$, el Gobierno impulsó una ley para hacer frente al problema de la financiación del terrorismo, que el Parlamento aprobó con amplísima mayoría ${ }^{28}$.

La resistencia de la argumentación jurídica para calificar como militante a una democracia que ha decidido emplearse a fondo en la lucha contra el terrorismo, no puede entenderse sino como el tributo que seguimos pagando a construcciones doctrinales propias de una época que ya no es la nuestra. Lo que a nosotros nos corresponde, como ciudadanos comprometidos con nuestro estilo de vida, es estar vigilantes para que la lucha contra el terrorismo no se convierta en una "carta blanca" letal para el Estado de Derecho.

${ }^{26}$ Véase la Decisión de la "Gran Sala" de 13 de febrero de 2003, así como la recaída en el caso Yazar, Karatas, Aksoy and People?s Labour Party (HEP) v36Turkey European Human Rights Repor(2ø03), 6, especialmente Párrafos 47-49.

${ }^{27}$ Me refiero al Editorial del International Herald Tridenen de junio de 2003, ("Dealing whith the Basques"), y a la respuesta de la ministra Ana Palacio, publicada en el mismo periódico el 2 de julio de 2003.

28 Ley 12/2003, de 22 de mayo, sobre "prevención y bloqueo de la financiación del terrorismo". Hay que destacar, así mismo, la Ley Orgánica 1/2003, de 10 de marzo, de "seguridad de los concejales y garantía de la democracia en los Ayuntamientos". La ley introduce reformas en una serie de leyes ordinarias y orgánicas, entre ellas la Ley de Bases del Régimen Local, para adicionar al supuesto de disolución de las Corporaciones Locales, cuando las mismas actúen de manera gravemente lesiva para el interés general, la presunción iuris et de iderque tal es el caso de los Ayuntamientos que adoptan reiteradamente Acuerdos, o incurren en actuaciones, que demuestren complicidad o apoyo, expreso o tácito, con el terrorismo. 